\title{
Fatigue Behavior of Rail Connections on $\cong$ Semi -High Speed and High Speed Rail Networks
}

\author{
J.Gayathiri , A.Venkatesh
}

\begin{abstract}
Rail joint is the most vulnerable and weakest part in the rail structure. Bolted rail joints and welded rail joints are the most predominantly used rail joints. In recent times, continuous welded rail joints are widely used. The literature study exhibits that the performance of welded rail joints are comparatively better than the bolted rail joints. This project mainly deals with the fatigue behavior of welded rail joints subjected to normal speed, semi-high speed and high speed rail networks with respect to rail joint location on the sleeper. The rail joint kept on two conditions, mainly rail joint on top of the sleeper and rail joint in between the sleepers. The model was created and the respective finite element analyses were made in ANSYS Workbench software. The rail joint was analyzed for the movement of wheel load on the rail for all speed conditions mentioned. The butt joint was given at the region of rail joint and the fatigue life results were obtained in the analyses made in ANSYS Workbench. The analyses methods covers the rail and wheel model creation, application of corresponding loads and supports and the simulation results were obtained. The simulation results portrays that when the continuous welded rail joint is located on the sleeper, the fatigue life of the rail joint in both the normal speed and semi-high speed conditions is higher when compared to the fatigue life of rail joint in high speed condition. And also when the welded rail joints are located in between two sleepers the rail joint in high speed rail networks provide increased fatigue life when compared with the rail joints located in normal and semi high speed conditions. This research provides a beneficiary effect and serves as a base for increasing the fatigue life of the rail networks.

Keywords: ANSYS Workbench, Butt joint, Continuous welded rail joints, fatigue, High speed rail, Semi high speed rail, Sleeper.
\end{abstract}

\section{INTRODUCTION}

Rail transport is one of the most prominent means of transportation. In recent times, the demand and usage of rail transportation has been increased to greater extent. By this increased utilization of rail transport system, different modes of failure may occur in the entire track components. Among the various track components, rail joint which serves as the connecting part between two rails is the most vulnerable and

Revised Manuscript Received on April 02, 2020.

* Correspondence Author

J.Gayathiri*, P.G. Student \& Corresponding Author, Department of Civil Engineering, Mepco Schlenk Engineering College, Sivakasi, Tamil Nadu, India. Email: gayathirijaganathan1@gmail.com

A.Venkatesh, Assistant Professor, Department of Civil Engineering, Mepco Schlenk Engineering College, Sivakasi, Tamil Nadu, India. Email: venkateshpersonnel@gmail.com

(c) The Authors. Published by Blue Eyes Intelligence Engineering and Sciences Publication (BEIESP). This is an open access article under the CC BY-NC-ND license (http://creativecommons.org/licenses/by-nc-nd/4.0/) easily deteriorating part [1]. Various investigations ensure that many numbers of derailments of trains have occurred mainly due to failure of rail joints [9]. In general, there are two types of rail joints. They are bolted rail joints and continuous welded rail joints. In continuous welded rail joints, generally two types of welding techniques are imparted, one is ash thermite welding and the other is flash butt welding [10]. The railway track components easily and frequently get subjected to repeated cyclic loads due to continuous passing of train. The continuous passing of train over the track results in fatigue failure of the corresponding components. Study on fatigue behavior of rail joint helps in increasing the performance of the rail joint assemblies [2].

In case of bolted rail joints the two rails are connected by fish plates, nut and bolt assemblies and minimum gap is left between two rails for insulation purpose [5]. When bolted rail joints are compared with the continuous welded rail joints, the dips and slips due to settlement of rail joints is higher in case of bolted rail connections than the continuous welded rail joints_8]. In the bolted rail joints the failure may also occur due to the effect of bolt looseness [4]. The presence of fatigue cracks in the region of rail end bolt holes results in derailment. The presence of residual hoop stress around the bolt holes helps in closure of initiated fatigue cracks [6]. Some study indicates that the effect of train load is higher than that of the axle load [11]. On comparing the two types of rail joints, continuous welded rail joints provide better performance than the bolted rail joints. Hence this project mainly deals with the fatigue life of the welded rail joint that is located on and in between the sleepers. In case of welded rail joints the failure gets increased when the length of the weld is lea than $150 \mathrm{~mm}$ with increasing depth of the weld [7]. Generally the fatigue failure occurs in stress concentrated zones and the regions of flaws in the structure. Stress concentration is generally found to higher in the region of defects and the welded zones. Flaws arise in the areas which have edge imperfections and irregularities over the surface [3].

In this project temperature effect for the rail and wheel model assembly was studied and fatigue life of automatic welded rail joint and butt welded rail joint for various types of rails under different cases with respect to the location of the sleepers has been studied. This study provides the base for the further investigation regarding the techniques to improve the fatigue life of the rail joints structures. 


\section{RESEARCH METHODS}

In this research fatigue behavior of welded rail joints under three rail conditions; normal speed, semi-high speed and high speed rail conditions based on the location of rail joint on the sleeper and in between the sleepers were studied using ANSYS Workbench software.

\section{A.Methodology}

In this research work, as an initial step the literature study was made in order to obtain basic idea about the works to be done. From the literature study it is clear that the behavior of welded rail joints is better than the bolted rail connections. As the next step of work, numerical analysis in ANSYS Workbench is done. In the numerical analyses the rail and the wheel model was created and the butt welding given between the two rails. Then the corresponding loads and supports were given to the rail and wheel assemblies and simulated results were obtained.

Table-I: Rail types for rail conditions

\begin{tabular}{|c|c|}
\hline Speed condition & Types of rail \\
\hline Normal speed rail & $50 \mathrm{~kg} / \mathrm{m}$ rail \\
\hline Semi high speed rail & $50 \mathrm{~kg} / \mathrm{m}$ rail \\
\hline High speed rail & $60 \mathrm{~kg} / \mathrm{m}$ and $73 \mathrm{~kg} / \mathrm{m}$ rail \\
\hline
\end{tabular}

Table- II: Specifications of rail

\begin{tabular}{|c|c|}
\hline \multicolumn{2}{|c|}{ Specification } \\
\hline Length of each rail & $1000 \mathrm{~mm}$ \\
\hline Width of the sleeper & $250 \mathrm{~mm}$ \\
\hline Gap between two sleepers & $600 \mathrm{~mm}$ \\
\hline
\end{tabular}

Types of rails used for normal speed, semi high speed and high speed rail conditions are mentioned in the Table I. The rail and the wheel model were modeled in ANSYS Workbench software. Welded connection was given between the two rails. The specification followed for the model creation is mentioned in the Table II.

\section{B. Finite Element Modeling}

In this research Finite element method is used to analyze the fatigue behavior of welded rail joints under two cases with respect to the rail joint locations. Three dimensional models of rail and wheel are created in ANSYS Workbench software and the corresponding analyses were made. The model of butt welded rail joint located on the sleeper along with its wheel and rail model for normal speed condition is show in the figure 1 . Fine meshing is provided in the joint region in order to obtain accurate solution.

\section{C.Loads and Support}

To attain proper results the load and support for the model should be defined properly. The model was given fixed support at the base at the sleeper locations. The total load acting on the wheel is calculated from the total tram car weight and the carrying capacity of the vehicle. The wheel and rail model for normal speed condition along with their corresponding loads and supports are shown in the figure 2.

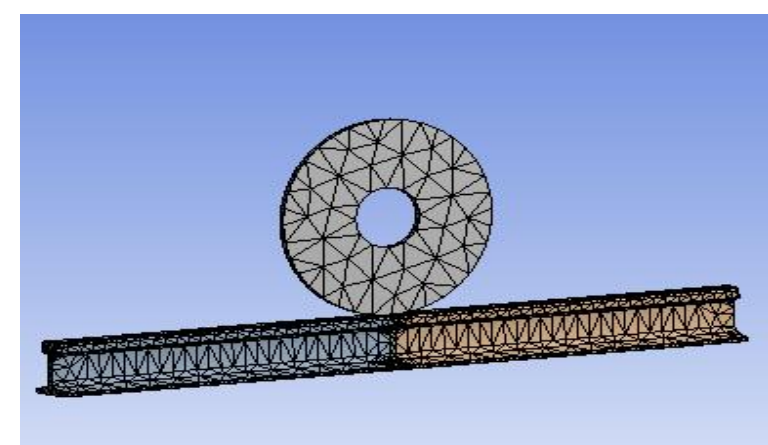

Fig.1. Wheel and rail model of butt welded rail joint under normal condition

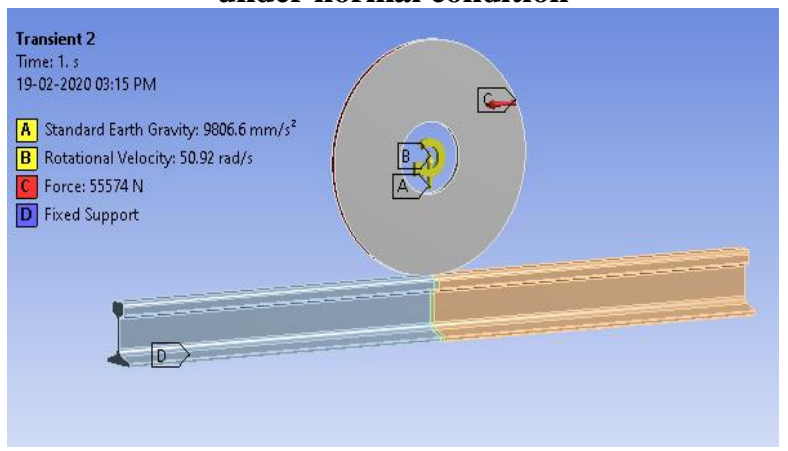

Fig.2. Loads and supports

\section{RESULTS AND DISCUSSION}

The finite element analyses were made and the simulation results were obtained by providing corresponding loads and supports to the rail and wheel assemblies. The results are obtained for the temperature effects of rail and wheel assembly and fatigue life cycle of automatic welded and butt welded rail joints located on the sleeper and in between the sleepers under normal speed, semi high speed and high speed rail conditions.

\section{A.Temperature Effects}

\section{Case I: Rail joint on the sleeper}

The zero fatigue cycles for welded rail joint located on the sleeper is obtained at the $150{ }^{\circ} \mathrm{C}$ hot temperature and $-100^{\circ} \mathrm{C}$ cold temperature for normal speed condition; $150^{\circ} \mathrm{C}$ hot temperature and $-150^{\circ} \mathrm{C}$ cold temperature for semi-high speed condition; $360^{\circ} \mathrm{C}$ hot temperature and $-270^{\circ} \mathrm{C}$ cold temperature for high speed $\left(60 \mathrm{~kg} / \mathrm{m}\right.$ rail) condition; $500^{\circ} \mathrm{C}$ hot temperature and $-275^{\circ} \mathrm{C}$ cold temperature for high speed (73kg/m rail) condition.

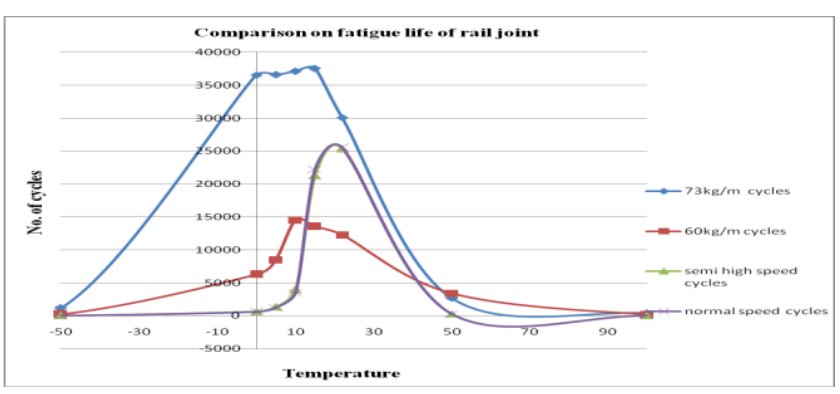

Fig.3. Temperature effects of rail joints on the sleeper under different rail conditions

Published By:

Blue Eyes Intelligence Engineering \& Sciences Publication

(C) CoDvriaht: All riahts reserved.

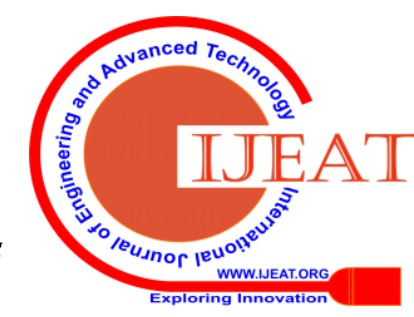




\section{Case II: Rail joint in between the sleepers}

The zero fatigue cycles for welded rail joint located in between the sleepers is obtained at the $350^{\circ} \mathrm{C}$ hot temperature and $-265^{\circ} \mathrm{C}$ cold temperature for normal speed condition; $345^{\circ} \mathrm{C}$ hot temperature and $-265^{\circ} \mathrm{C}$ cold temperature for semi-high speed condition; $375^{\circ} \mathrm{C}$ hot temperature and $-275^{\circ} \mathrm{C}$ cold temperature for high speed $(60 \mathrm{~kg} / \mathrm{m}$ rail) condition; $395^{\circ} \mathrm{C}$ hot temperature and $-280^{\circ} \mathrm{C}$ cold temperature for high speed $(73 \mathrm{~kg} / \mathrm{m}$ rail) condition.

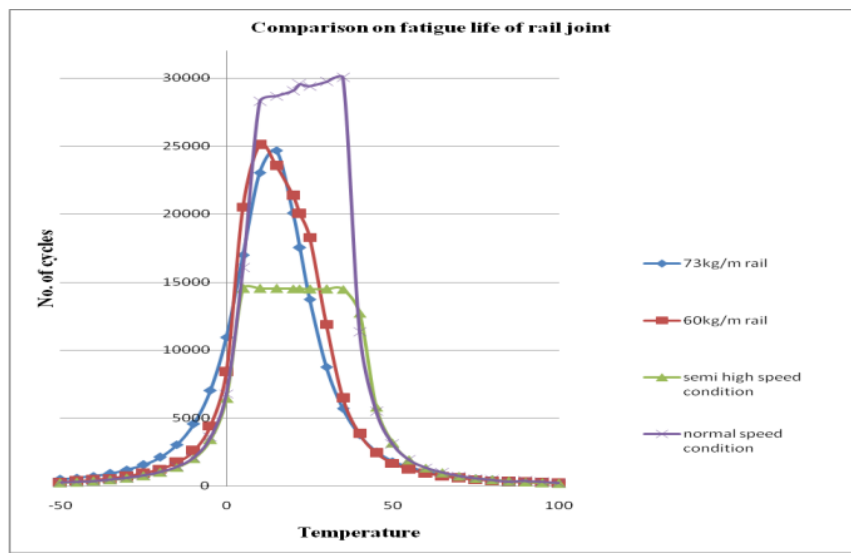

Fig.4. Temperature effects of rail joints between the sleepers under different rail conditions

\section{B.Automatic Welding}

Case I: Rail joint on the sleeper

A. Normal speed rail condition

The minimum fatigue life of automatic welded rail joint on the sleeper under normal speed condition is 13169 cycles.

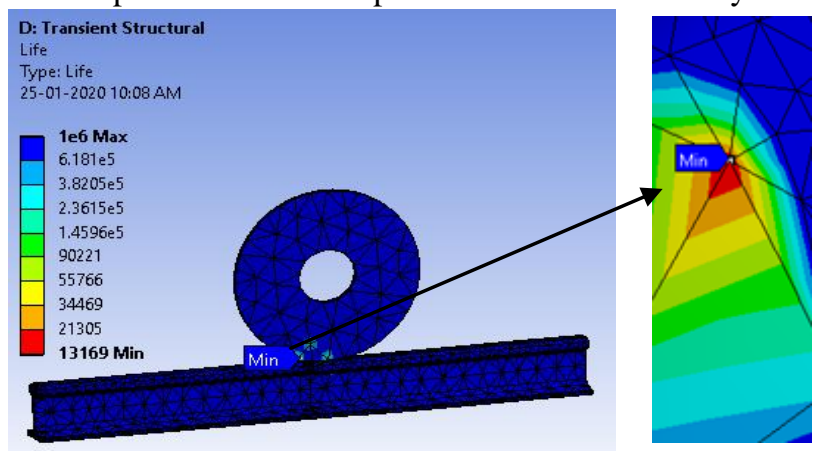

Fig.5. Minimum fatigue life of automatic welded rail joint on the sleeper under normal speed condition

\section{B.Semi high speed rail condition}

The minimum fatigue life of automatic welded rail joint on the sleeper under semi high speed condition is 13348cycles.

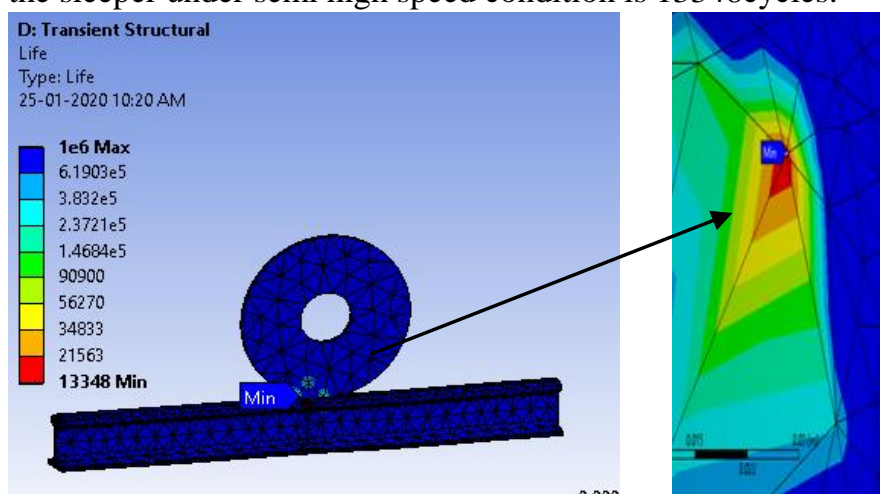

Fig.6.Minimum fatigue life of automatic welded rail joint on the sleeper under semi high speed condition

C.High speed rail condition $(60 \mathrm{~kg} / \mathrm{m}$ rail)

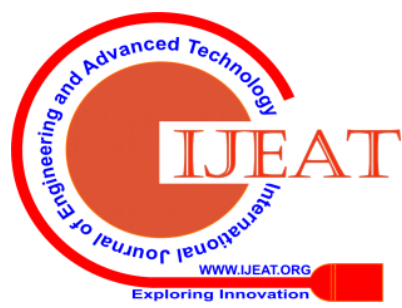

on the sleeper under high speed condition $(60 \mathrm{~kg} / \mathrm{m}$ rail) is 14619 cycles.

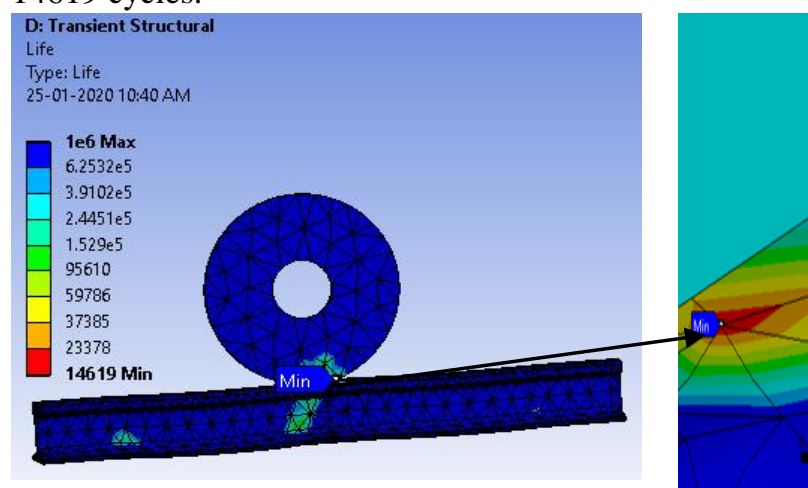

Fig.7.Minimum fatigue life of automatic welded rail joint on the sleeper under high speed condition $(60 \mathrm{~kg} / \mathrm{m}$ rail $)$ D.High speed rail condition ( $73 \mathrm{~kg} / \mathrm{m}$ rail) 23721cycles.

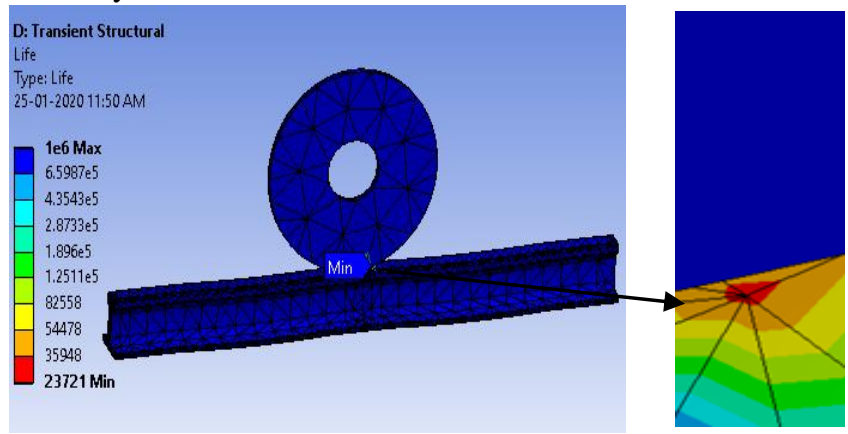

Fig.8.Minimum fatigue life of automatic welded rail joint on the sleeper under high speed condition $\quad(73 \mathrm{~kg} / \mathrm{m}$ rail)

Case II: Rail joint between the sleepers

A. Normal speed rail condition

The minimum fatigue life of automatic welded rail joint cycles.

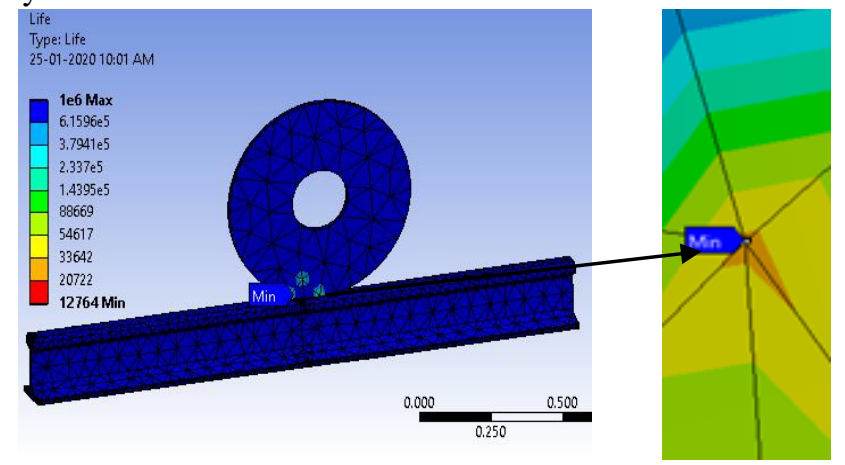

Fig.9. Minimum fatigue life of automatic welded rail joint between the sleepers under normal speed condition

B. Semi high speed rail condition

The minimum fatigue life of automatic welded rail joint between the sleepers under semi high speed condition is 23254 cycles. 


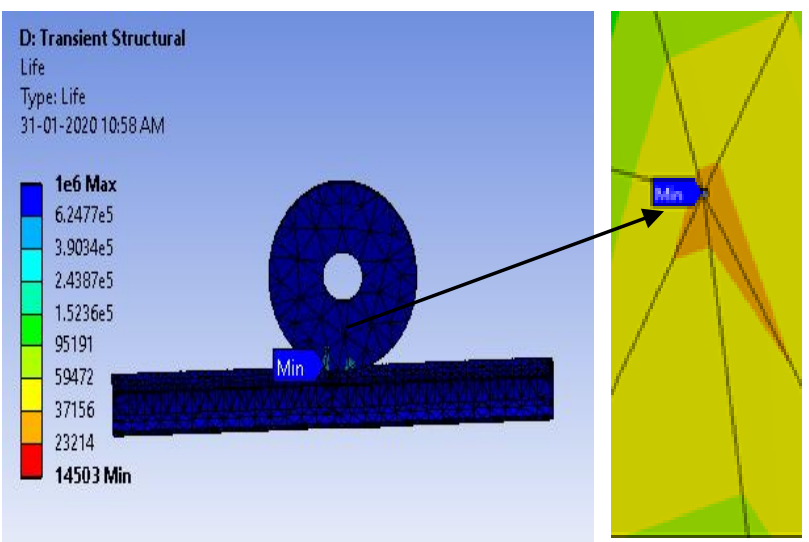

Fig.10. Minimum fatigue life of automatic welded rail joint between the sleepers under semi high speed condition

\section{B.High speed rail condition $(60 \mathrm{~kg} / \mathrm{m}$ rail)}

The minimum fatigue life of automatic welded rail joint between the sleepers under high speed condition $(60 \mathrm{~kg} / \mathrm{m}$ rail) is 20913 cycles.
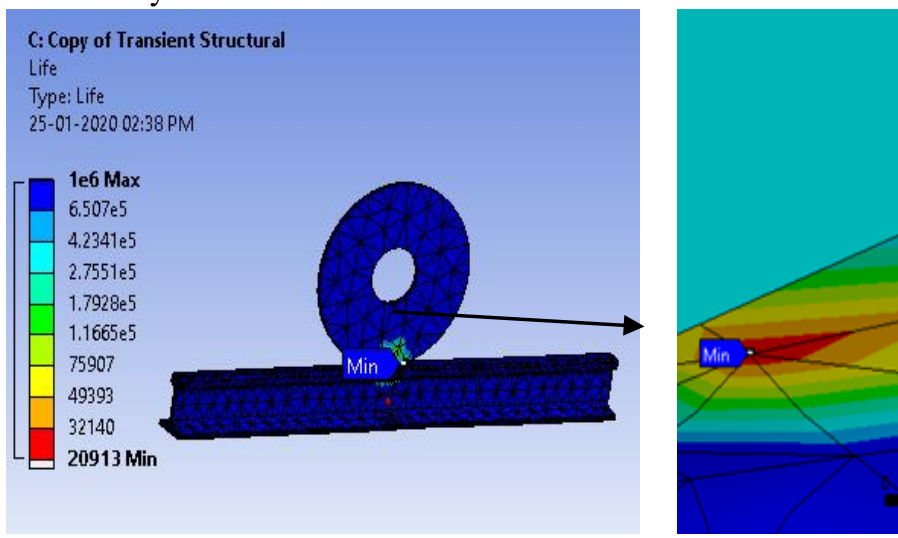

Fig.11.Minimum fatigue life of automatic welded rail joint between the sleepers under high speed condition $(60 \mathrm{~kg} / \mathrm{m}$ rail)

\section{High speed rail condition $(73 \mathrm{~kg} / \mathrm{m}$ rail)}

The minimum fatigue life of automatic welded rail joint between the sleepers under high speed condition $(73 \mathrm{~kg} / \mathrm{m}$ rail) is 87943 cycles.
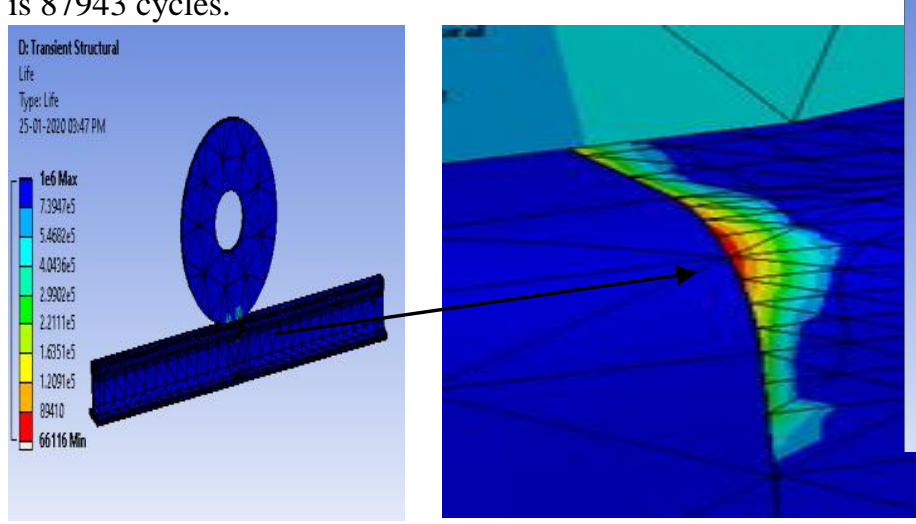

Fig.12.Minimum fatigue life of automatic welded rail joint between the sleepers under high speed condition (73kg/m rail)

\section{C.Butt Welding}

Case I: Rail joint on the sleeper

\section{A. Normal speed rail condition}

The minimum fatigue life of butt welded rail joint on the sleeper under normal speed condition is 41415 cycles.

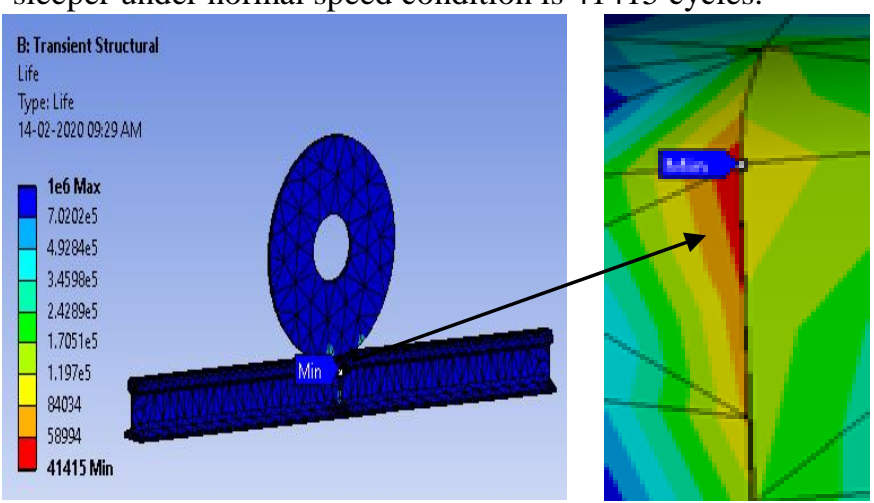

Fig.13.Minimum fatigue life of butt welded rail joint on the sleeper under normal speed condition

\section{B. Semi high speed rail condition}

The minimum fatigue life of butt welded rail joint on the sleeper under semi high speed condition is 41431cycles.

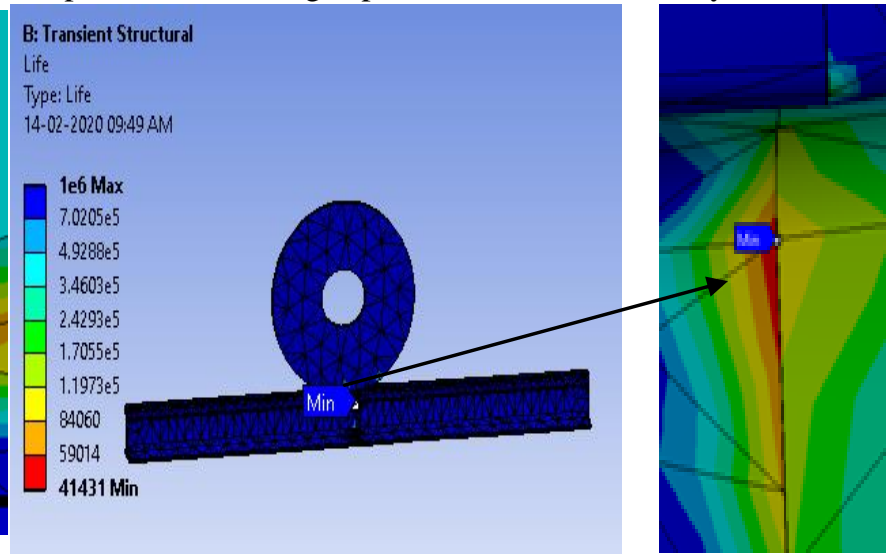

Fig.14.Minimum fatigue life of butt welded rail joint on the sleeper under semi high speed condition

C. High speed rail condition $(60 \mathrm{~kg} / \mathrm{m}$ rail)

The minimum fatigue life of the butt welded rail joint on the sleeper under high speed condition (60 kg/m rail) is 41528 cycles.

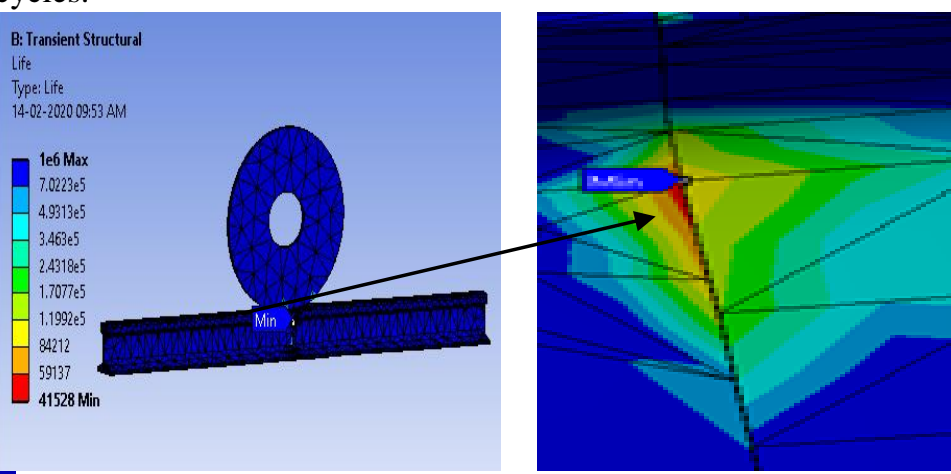

Fig.15.Minimum fatigue life of butt welded rail joint on the sleeper under high speed condition $(60 \mathrm{~kg} / \mathrm{m}$ rail)

\section{High speed rail condition ( $73 \mathrm{~kg} / \mathrm{m}$ rail)}

The minimum fatigue life of butt welded rail joint on the sleeper under high speed condition $(73 \mathrm{~kg} / \mathrm{m}$ rail) is 82451cycles.

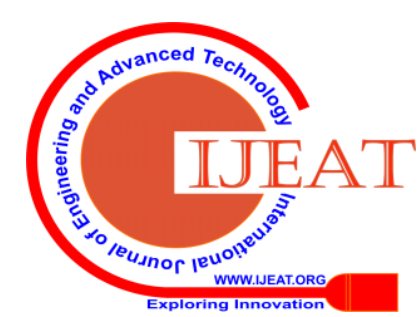




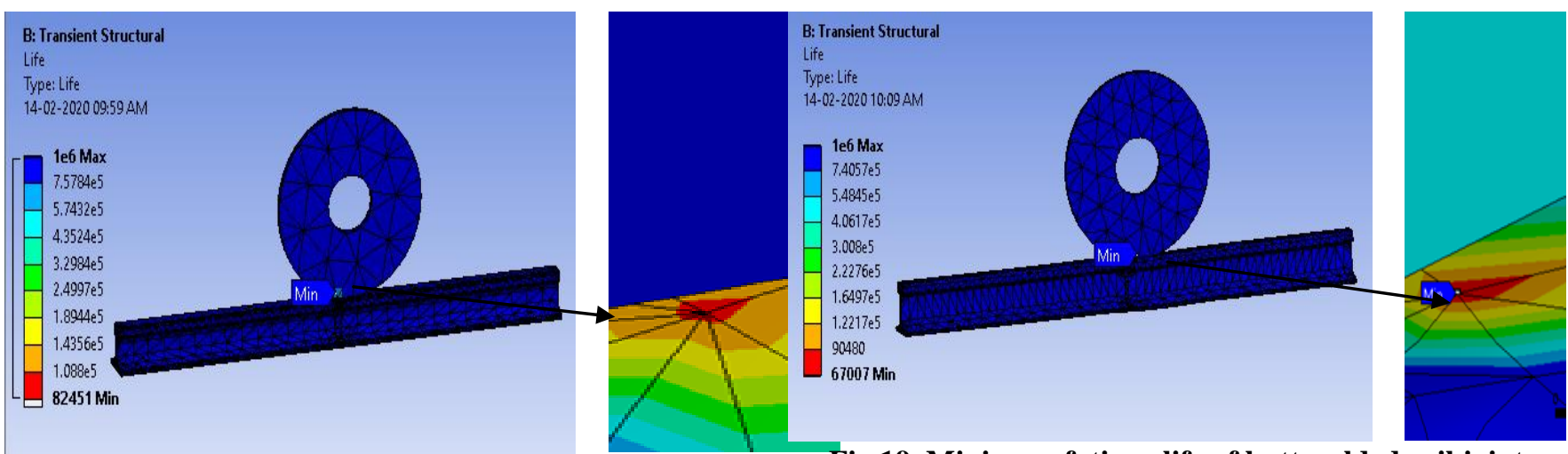

Fig.16. Minimum fatigue life of butt welded rail joint on the sleeper under high speed condition $\quad(73 \mathrm{~kg} / \mathrm{m}$ rail)

Fig.19. Minimum fatigue life of butt welded rail joint between the sleepers under high speed condition $(60 \mathrm{~kg} / \mathrm{m}$ rail)

\section{Case II: Rail joint between the sleepers}

\section{A. Normal speed rail condition}

The minimum fatigue life of butt welded rail joint between the sleepers under normal speed condition is 25053 cycles.

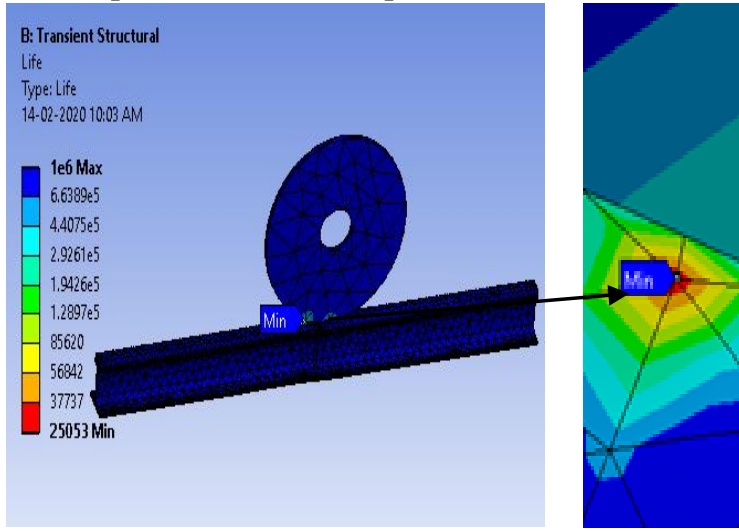

Fig.17.Minimum fatigue life of butt welded rail joint between the sleepers under normal speed condition

\section{B. Semi high speed rail condition}

The minimum fatigue life of butt welded rail joint between the sleepers under semi high speed condition is 24977 cycles.

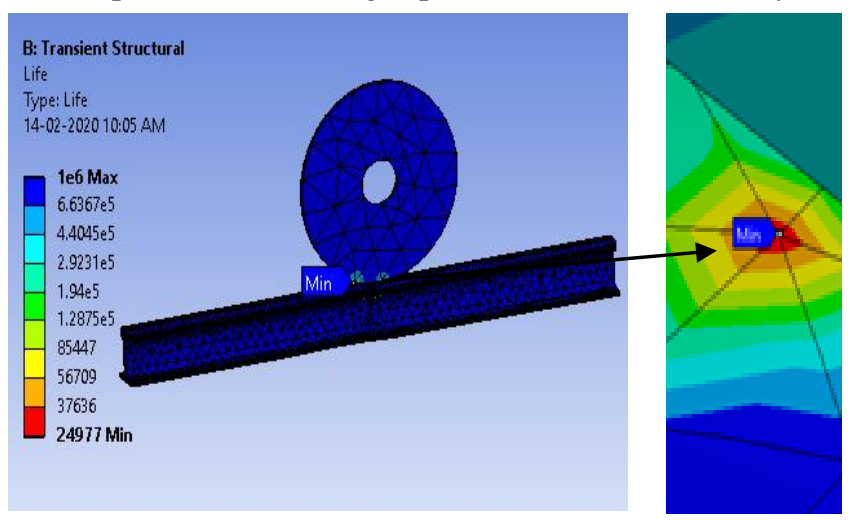

Fig.18. Minimum fatigue life of butt welded rail joint between the sleepers under semi high speed condition

\section{High speed rail condition $(60 \mathrm{~kg} / \mathrm{m}$ rail)}

The minimum fatigue life of butt welded rail joint between the sleepers under high speed condition $(60 \mathrm{~kg} / \mathrm{m}$ rail) is 67007 cycles.

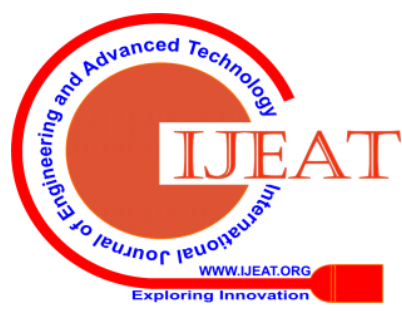


Table-III: Fatigue life cycles of butt welded rail joints

\begin{tabular}{|c|c|c|}
\hline \multirow{2}{*}{ Rail conditions } & \multicolumn{2}{|c|}{ Number of fatigue life cycles } \\
\cline { 2 - 3 } & $\begin{array}{c}\text { Rail joint on the } \\
\text { sleeper }\end{array}$ & $\begin{array}{c}\text { Rail joint in } \\
\text { between the } \\
\text { sleepers }\end{array}$ \\
\hline $\begin{array}{c}\text { Normal speed } \\
\text { condition }\end{array}$ & 41415 cycles & 25053 cycles \\
\hline $\begin{array}{c}\text { Semi- high speed } \\
\text { condition }\end{array}$ & 41431 cycles & 24977 cycles \\
\hline $\begin{array}{c}\text { High speed } \\
\text { condition (60kg/m } \\
\text { rail) }\end{array}$ & 41528 cycles & 67007 cycles \\
\hline $\begin{array}{c}\text { High speed } \\
\text { condition (73kg/m } \\
\text { rail) }\end{array}$ & 82451 cycles & 174630 cycles \\
\hline
\end{tabular}

\section{CONCLUSION}

In this analyses; the fatigue life of butt jointed continuous welded rail joint under corresponding loads and supports were obtained. The results were obtained for two cases based on the location of rail joints with respect to the sleepers.

The simulation results exhibits that the fatigue life of normal speed and semi high speed condition is higher when the rail joint is on the sleeper. The fatigue life of high speed rail condition is higher when the rail joint is in between the sleepers. Also the temperature of the rail plays an important role in fixing the fatigue life. The optimum operating temperature range for getting a good fatigue life for the rail is from -50 to $100^{\circ} \mathrm{C}$, excluding this range, the fatigue life diminishes drastically to zero.

This paper suggests that butt welded rail joint for normal speed and semi high speed should be located on the sleepers and for high speed rail condition, the butt welded rail joint should be in between the sleepers.

\section{ACKNOWLEDGMENT}

The authors wish to thank all the members for their help and guidance in this project. The authors are not having any conflicts of interest in publishing the results.

\section{REFERENCES}

1. AmolY.Chaudhari, P. (2014). Analysis and experimental investigation of rail joint to improve fatigue life using cold expansion process. IOSR journal of mechanical and civil engineering , 81-84.

2. Chapetti M.D., J. L. (2011). Estimating the fatigue behavior of welded joints. Engineering Procedia , 959-964.

3. Chen, Y.-C. C.-W. (2006). Effects of Insulated rail joint on wheel/rail contact stresses under the condition of partial slip. Wear, ELSEVIER , 1267-1273.

4. Ding K, D. M. (2006). Flexural behavior of bonded bolted butt joints due to bolt looseness. Advances in Engineering Software , 598-606.

5. El-Sayed H.M, M. ,. (2018). A three dimensional finite element analysis of insulated rail joints. Engineering failure analysis , 201-215.

Published By:

Blue Eyes Intelligence Engineering \& Sciences Publication

(C) Cobvriaht: All riahts reserved.
6. Galya V.Duncheva, J. T. (2013). A new approach to enhancement of fatigue life of rail-end-bolt holes. Engineering Failure analysis, ELSEVIER , 167-179.

7. J, L. C. (2018). Fatigue prediction of welded joints. International journal of Fatigue, ELSEVIER , 78-87.

8. NaanZong, H. A. (2013). Service conditionof insulated rail road corridors around the insulated rail joints. Journal of Transport engineering, ASCE library, 643-650.

9. Samantaray S.K. and Mittal S.K. et al. (2019). Assessing the flexion behavior of bolted rail joints using finite element analysis. Engineering Failure analysis, ELSEVIER , 142-153.

10. Tilahun, S. a. (2016). Stress analysis of Rail joint under Wheel load. International Journal of Innovative science, engineering and Technology, 526-543.

11. Wu Cai and Zefeng Wen et al. (2007). Dynamic Stress analysis of rail joint with height differencedefect using finite element method. Engineering Failure analysis, ELSEVIER , 1488-1499.

\section{AUTHORS PROFILE}

J.Gayathiri, She is Graduated B.E. Civil Engineering in Ramco Institute of Technology, Rajapalayam, in the year 2018. She is currently pursuing het M.E. Structural Engineering in Mepco Schlenk Engineering College, Sivakasi.

A.Venkatesh, M.E.. Having a masters degree in Structural Engineering, he is working as Assistant Professor in the Department of Civil Engineering, Mepco Schlenk Engineering College, Sivakasi. He is a life member in ISTE(Indian Society of Technical Education) and SEA (Safety Engineers Association). He is also having his International General Certificate through NEBOSH Apart from Academics, he is also having his diploma degree in Acupuncture. $\mathrm{He}$ also has 4.5 years of construction EHS experience from L\&T Construction.He is been in the current position for the last 3 years. 